\title{
Ultrasound Diagnosis of Complete Rotator Cuff Tear
}

\author{
Abdullaiev RYa*1, Kulikova FI ${ }^{4}$, Dudnik TA ${ }^{2}$, Baibakov $\mathrm{V}^{4}$, Davlietova $\mathrm{N}^{3}$ and Dihtiar VA ${ }^{3}$ \\ ${ }^{1}$ Kharkov Medical Academy of Postgraduate Education, Ukraine \\ ${ }^{2}$ Poltavsk Medical Academy, Ukraine \\ ${ }^{3}$ Dnipropetrovsk Medical Academy, Ukraine \\ ${ }^{4}$ Dnipro Medical Institution of traditional and alternative medicine, Ukraine
}

*Corresponding author: Rizvan Abdullaiev, Department of Ultrasound Diagnostics, Kharkov Medical Academy of Postgraduate Education, Ukraine

\begin{tabular}{|c|c|}
\hline ARTICLE INFO & ABSTRACT \\
\hline Received: 幽 February 11, 2019 & Citation: Abdullaiev RYa, Kulikova FI, Dudnik TA, Baibakov V, Davlietova N, Dihtiar VA. \\
\hline Published: 幽 February 20, 2019 & $\begin{array}{l}\text { Ultrasound Diagnosis of Complete Rotator Cuff Tear. Biomed J Sci \& Tech Res 14(5)-2019. } \\
\text { BJSTR. MS.ID.002615. }\end{array}$ \\
\hline
\end{tabular}

\section{Introduction}

Pain is the most common complaint in patients with rotator cuff injuries. The rotator cuff is a group of muscles and tendons that surround the shoulder joint, keeping the head of your upper arm bone firmly within the shallow sock-et of the shoulder. As a rule, pain is localized in the posterior or lateral regions, at the site of attachment of the deltoid muscle to the humerus. Pain syndromes in the shoulder joint area may be local (usually with an injury) or have a reflex nature. It is not always possible to distinguish the true localization of pain, as they are caused not only by damage to the shoulder joint, but also by the con-dition of the cervical spine. Diagnosis of the pathology of the shoulder joint is often carried out on the basis of X-ray, computed tomography (CT) and magnetic resonance imaging [1]. In recent years, ultrasonography is increasingly used to diagnose the pathologies of the soft tissues of the musculoskeletal system [2-5].

\section{Objective}

To study the possibilities of two-dimensional echography in the diagnosis of complete rotator cuff tear.

\section{Materials and Methods}

A retrospective analysis of the results of ultrasound studies of the shoul-der in 54 patients ( 32 men and 22 women) aged 20-73 years operated on for the rupture of the rotator cuff (RMP) was carried out. The comparative group consisted of 19 healthy patients without any complaints about the pathology of the shoulder joint. All patients underwent MRI and X-ray of the shoulder joint. The ultrasonic examination was carried out on Logiq 7 (QE) scanners by linear transducers with a frequency of $5-12 \mathrm{MHz}$ by means of poly projection and polyposive scanning of RMP using functional ultrasonography and color Doppler mapping. The following ultrasonographic symptoms were assessed: homogeneity, echogenicity, integrity of tendon contours, presence of effusion in bags and tendon sheaths, the number of vascular signals in the affected area during color and energy Doppler mapping, the results of functional tests as needed.

\section{Results}

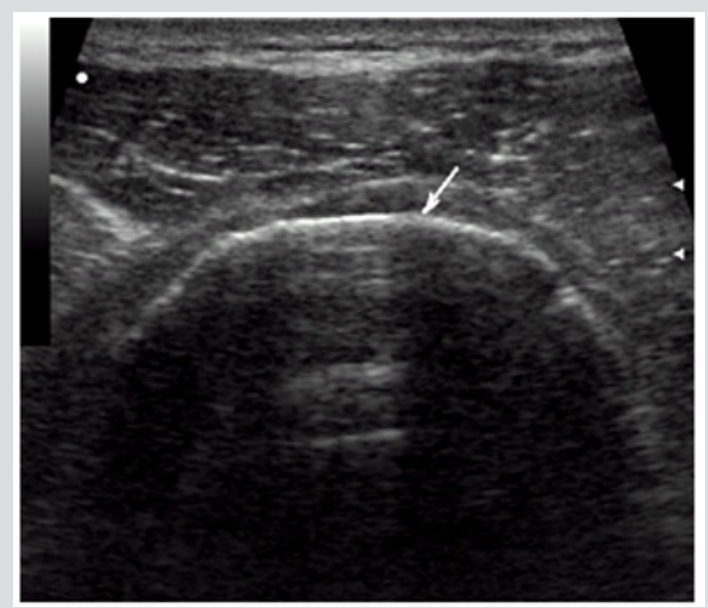

Figure 1: Echogram of complete rupture of the rotator cuff. There is no imaging of the tendons in a typical place, the contour of the humeral head is bare, the deltoid muscle is adjacent to it is visualized. 
A complete rupture of the rotator cuff against the background of acute in-jury occurred in $64.8 \%$ of cases, against the background of chronic injury - in $35.2 \%$ of cases, respectively ( $\mathrm{P}<0.05$ ). The absence of tendon imaging in a typical place was detected in $70 \%$ of cases, while in the sonogram the humeral head contour was determined (70\%) with adjoining the deltoid muscle (70\%). Such an echographic picture corresponded to a massive rupture of a rotator cuff with damage to several tendons. In $96 \%$ of cases, complete rupture of the rotator cuff of the shoulder was accompanied by effusion in the subdeltoid-subacromial bag, in $90 \%$ of cases the effusion had a heterogeneous structure with hyperechoic inclusions, indicating the organization of the hematoma. In $57 \%$ of cases with identified effusion in the wall of the sub-deltoid-subacromial bag there was an increase in vascularization (Figures 1-4).

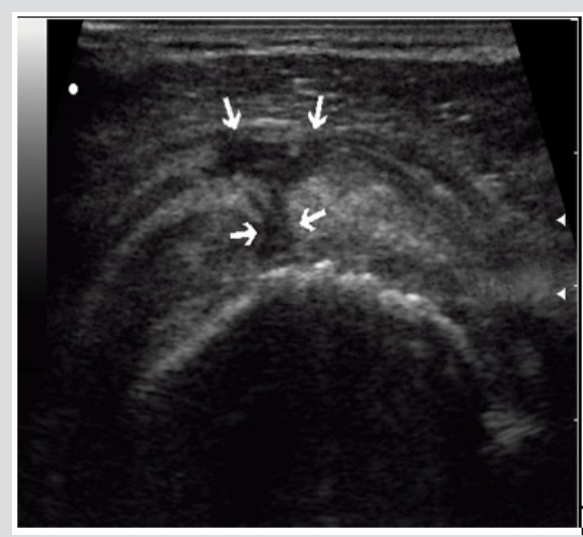

Figure 2: Echogram of complete rupture of the rotator cuff. Intermittent rotator cuff with a diasta-sis of broken tendon ends. The fistula with subdeltoid-subacromial bag is visualized (arrows).

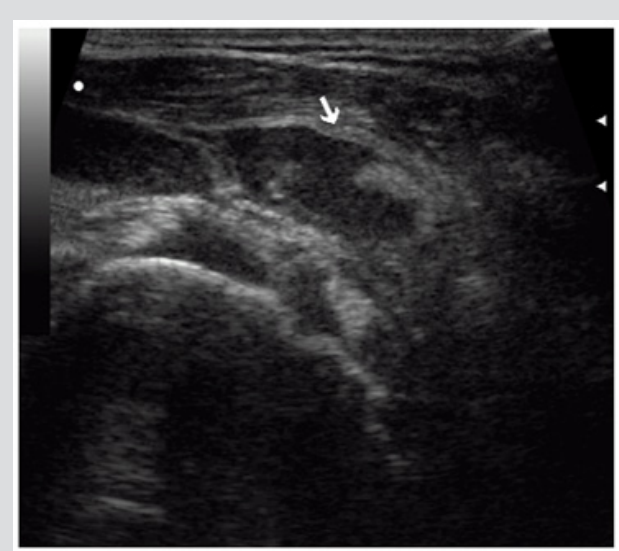

Figure 3: Echogram of hemorrhagic sub-deltoidsubacromial bursitis with a massive rupture of rota-tor cuff. Effusion heterogeneous structure with areas of the organization of hematoma (arrow).

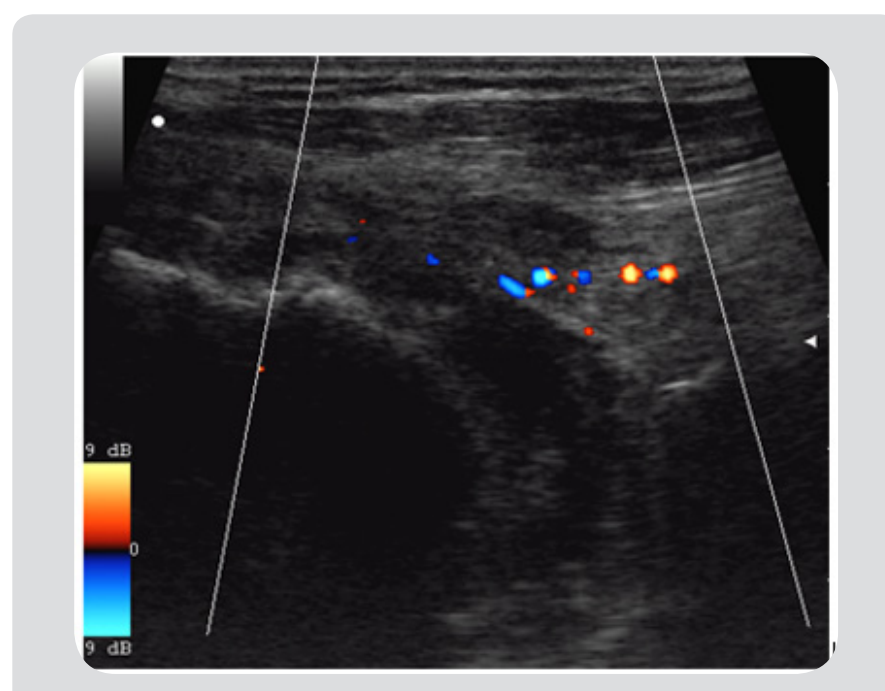

Figure 4: The rupture of the supraspinatus, massive hemorrhagic bursitis.

\section{Conclusion}

The diagnosis of RMP rupture included: lack of tendon imaging in a typi-cal place, discontinuity of contours, visualization of the ends of a torn tendon, bare contour of the humeral head, presence of focal cartilage fragments of the humeral head, adherence of the deltoid muscle to the head of the humerus, anastomosis with subdeltoid-subacromial bag (SSB), effusion in it and in the synovial vagina of the biceps tendon, heterogeneity of effusion, increased vas-cularization in the area of the tendon defect and on the wall of the SSB.

\section{References}

1. Beggs I (2011) Shoulder ultrasound. Semin Ultrasound CT MR 32(2): 101-113.

2. McNally EG, Rees JL (2007) Imaging in shoulder disorders. Skeletal Radiol 36(11): 1013-1016.

3. Beggs I (2011) Shoulder ultrasound. Semin Ultrasound CT MR 32(2): 101-113.

4. Smith TO, Back T, Toms AP, Hing CB (2011) Diagnostic accuracy of ultrasound for rotator cuff tears in adults: A systematic review and metaanalysis. Clin Radiol 66(11): 1036-1048.

5. Abdullaev RY, Dzyak GV, Dudnik TA (2010) Ultrasonography of the shoulder joint. Kharkov, Ukraine. 


\section{ISSN: 2574-1241}

DOI: 10.26717/BJSTR.2019.14.002615

Rizvan Abdullaiev. Biomed J Sci \& Tech Res

(C) (i) This work is licensed under Creative

Submission Link: https://biomedres.us/submit-manuscript.php

A Assets of Publishing with us
BESEARCHES
- Global archiving of articles
- Immediate, unrestricted online access
https://biomedres.us/

